\title{
DECISION MAKING PROCESSES AND THE ADOPTION OF ENERGY SAVING TECHNIQUES IN SOCIAL HOUSING
}

\author{
A.G. ENTROP Ir. ${ }^{1}$ \\ G.P.M.R. DEWULF Prof. Dr. ${ }^{1}$ \\ ${ }^{1}$ Department of Construction Management \& Engineering, University of Twente, PO \\ Box 217, 7500AE Enschede, the Netherlands, a.g.entrop@utwente.nl, \\ g.p.m.r.dewulf@utwente.nl
}

Keywords: stakeholders, decision making, energy saving, residential real estate

\begin{abstract}
Summary
Many innovative techniques and large policy measures have been introduced to reduce energy consumption. Despite the high ambitions and societal pressures, the adoption rate of energy measures is still low. Using adoption theories this paper provides a framework to analyse the adoption process of energy saving techniques in building processes. The stakeholders in the adoption process of energy measures are analysed during every phase of a building project. This framework is used to analyse four projects of a social housing corporation. The low rate of adoption of energy saving techniques can be explained by the large number and variety of stakeholders involved.
\end{abstract}

\section{Introduction}

The energy consumption in the built environment accounts for more than forty per cent of the total energy consumption in Europe (EC, 2002). Improving the energy performance of the built environment has an important impact on the reduction of carbon dioxide emissions and sustainability in general. Many innovative techniques have been introduced to lower the energy consumption or to use renewable energy sources, but not all techniques have been broadly adopted.

There is a large variety of innovative techniques. They differ in terms of complexity and costs. In some cases new techniques can directly replace the conventional product, in other cases large adjustments in the building have to be made. Energy saving techniques can reduce life-cycle costs, but often lead to higher investment costs. Although many measures are widely accepted in society and high ambitions regarding the energy performance of the forthcoming building are often expressed during the initial phase of a building project, these ambitions are not always realised in practice. We are aware that policy-measures might not have the expected impact if there is a lack of social acceptation of those measures (see e.g. Raven 2006). Therefore sustainable energy measures will not be successfully implemented as long as we do not have a clear understanding of the behavior of the users, where we interpret the term 'user' as stakeholders in the construction process: architects, developers, builders, clients and end-users, i.e. consumers. We expect that this is due to the influence of specific stakeholders in the design and construction process of buildings.

Our objective is to make a contribution to the knowledge on decision making processes by developing a framework to analyse the influence on the adoption of energy saving techniques by stakeholders involved in building processes. Our framework is based on innovation adoption theories. We focused on the 
stakeholders who are involved in the adoption process of innovative techniques that lower the energy consumption or make use of renewable energy sources. The case studies are building (re)design processes in social housing.

It is expected that the stakeholders involved in the building process are of influence on the adoption process (Cooke et al, 2007), whereby the ambitions stated by the clients before construction and the actual energy performance after construction often do not correspond with each other. In a building process some organisations or persons are only for a limited time path involved and all have different interests and targets. Therefore, many individual reasons to adopt or to reject energy techniques can exist.

\section{Developing a framework to analyse adoption in building processes}

In this section we will first address the adoption theory as presented by Rogers (2003). Then the context, in which adoption processes take place, will be discussed, before presenting specific characteristics of building processes.

\subsection{Adoption theory in general}

Many studies have been published on adoption of innovations. Well-known is the work of Rogers that gives insights in which characteristics of energy saving techniques are relevant, how the adoption process can be phased, and which kind of adopters exist. His work is being used to come to a framework on the adoption process of energy saving techniques in the built environment.

Rogers (2003, pp. 12) states that: an innovation is an idea, practice, or object that is perceived as new by an individual or other unit of adoption. In this paper the idea, practice, or object are techniques that lower the energy consumption or techniques that make it possible to fulfil the need for energy in a renewable way. The individual or other unit of adoption in building projects are a variety of stakeholders. A stakeholder is in our case an individual or organisation with an interest or concern in a building project. Not all stakeholders can exert influence on the progress and outcomes of a building project. The group of stakeholders that can exert influence is further referred to in this paper as 'actors'.

Rogers (2003) defines five attribute that strongly influence the rate of adoption of innovations, namely relative advantage, compatibility, complexity, trialability and observability. This means for example that a high level of complexity will more likely result in a lower adoption of an innovative energy saving techniques than a low level of complexity. In the process of adopting or rejecting an innovation five phases are distinguished, namely (ibid., pp. 171-189):

1. Knowledge: in this stage an individual (in our case actor) is exposed to an innovation's existence and gains an understanding of how it functions;

2. Persuasion: the individual forms a favourable or unfavourable attitude toward the innovation. The mentioned perceived attributes are important in this stage;

3. Decision: activities are undertaken that lead to a choice to adopt or reject an innovation;

4. Implementation: this occurs when an individual puts an innovation to use;

5. Confirmation: in this stage the individual seeks to avoid a state of dissonance or to reduce it if it occurs. 


\subsection{Adoption processes in their context}

Dieperink et al. (2004) and Hartmann et al. (2008) stress the importance of studying adoption in its context. The framework of Dieperink et al (2004) expands Roger's model by linking the adoption process with macro developments, technical aspects, economic aspects and the company's context. The specific characteristics of the context have to be understood in order to analyse the decision-making process of innovations.

The integrative model of Dieperink et al. explaining the diffusion of innovations offers a detailed structure to align motivations and arguments of actors for adopting or rejecting energy saving techniques. Vermeulen et al. (2006) elaborates on the model of Dieperink et al. (2004) by specifying first and second level variables, which explain the adoption of energy innovations for new office buildings. They mention that the actor's characteristics and the networks in which the actor participates have impact on the decision making process and therefore on the adoption rate. This network forms the heart of our framework.

Research of Hartmann et al (2008) focuses on the adoption of innovations by professional public clients, in which four conflicting factors were strongly affecting the innovation perception of this actor. Hartmann et al. (2008) offer a model of the adoption process that links the public dimension and professional dimension of the client with the innovation perception. These scholars see risk as an important additional innovation attribute. Their model describes the deliberation process underlying the adoption process.

Based on these studies we distinguish four contextual dimensions, namely: the characteristics of the actors, the context of the project, the macro developments, and the state of technology. The last one is based on Dieperink's "technical aspects" and Hartmann's attribute "risk". By specifying which techniques are in which stage of the innovation life cycle, risks can partially be assessed.

\subsection{Adoption processes in the construction industry}

Building projects can be characterised as inter-organisational projects. In building projects, where organisational connections exist adjacent to inter-organisational connections, decisions are taken in a complex context. In every phase of the building process actors and stakeholders join or leave. The different phases of building processes can be profoundly explained by using the process protocol of the University of Salford as specified in Table 1.

Table 1: Phases in the design and construction process (Kagioglou, et al., 1998).

\begin{tabular}{ll}
\hline \multicolumn{1}{c}{ Group } & \multicolumn{1}{c}{ Phases } \\
\hline Pre-project phases & O. Demonstrating the need \\
\cline { 2 - 2 } & I. Conception of need \\
\cline { 2 - 2 } & II. Outline feasibility \\
\cline { 2 - 2 } & III. Substantive feasibility study \& outline financial authority \\
\hline Pre-construction phases & IV. Outline conceptual design \\
\cline { 2 - 2 } & V. Full conceptual design \\
\cline { 2 - 2 } & VI. Production design procurement \& full financial authority \\
\hline Construction phases & VII. Production information \\
\cline { 2 - 2 } & VIII. Construction \\
\hline Post completion phase & IX. Operation \& maintenance \\
\hline
\end{tabular}

This arrangement shows from a certain perspective some similarities compared to the innovation decision process of Rogers. The awareness of a certain necessity and generating an attitude are prevailing in the first phases (phase 1 and 2). In the 
final drawings and documents, before setting a price for construction, adoption or rejection decisions need to be taken (phase 3 ). The construction process needs to cope with the installation procedure for the specific energy techniques (phase 4). In the end the user of the building will experience if the techniques perform and really can save energy (phase 5).

In the building process we consider ten actors to have direct influence in the adoption or rejection of energy saving techniques (see Table 2). The actors are involved in different stages of the building process. The trajectory to come from an energy saving concept to specific energy saving techniques, the contextual factors influencing the process, and the roles of the actors are included in our framework (see Figure 1). The five phases of Rogers are expected to be only partially in line with the phases of the general design and construction process. Individual actors are persuaded and are taking decisions on energy saving measures at different stages in the process. In other words, the overall diffusion process consists of various personal adoption cycli which vary per actor.

Table 2: Descriptions of the ten actors regarded in this research

\begin{tabular}{|c|c|c|}
\hline & Actor & Description \\
\hline \multirow{6}{*}{ 窇 } & Client-Principal $(\mathrm{Cl})$ & $\begin{array}{l}\text { Person or organisation requesting the constructive service of a professiona } \\
\text { person or organisation. In some cases a client can be a property developer. }\end{array}$ \\
\hline & Customer- User $(\mathrm{Cu})$ & Person or organisation making use of the provided buildin \\
\hline & Warden $(\mathrm{W})$ & $\begin{array}{l}\text { Person or organisation responsible for the supervision of and maintenance } 0 \\
\text { the building and its location }\end{array}$ \\
\hline & $\begin{array}{l}\text { Property developer } \\
\text { (PD) }\end{array}$ & $\begin{array}{l}\text { Person or organisation that converts land to a new purpose, especially b: } \\
\text { constructing buildings }\end{array}$ \\
\hline & Project manager (PM) & $\begin{array}{l}\text { Person that plans, organizes, and allocates resources to come to a successfu] } \\
\text { completion of a specific project (as specified by the client) }\end{array}$ \\
\hline & Municipality (Mu & $\begin{array}{l}\text { A town or district having a local government that enforces buildin } \\
\text { regulations }\end{array}$ \\
\hline \multirow{5}{*}{ 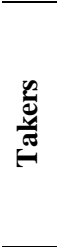 } & Architect (A) & Person who designs buildings and in most cases supervises their constructic \\
\hline & Consultant (Cs) & Person or organisationthat provides expert advice professionally \\
\hline & Contractor (Co) & $\begin{array}{l}\text { Organisation or person that undertakes a contract to provide materials and/or } \\
\text { labour for a construction project }\end{array}$ \\
\hline & Subcontractor (Sc) & $\begin{array}{l}\text { Organisation or personthat carries out work for a company as part of a larger } \\
\text { project }\end{array}$ \\
\hline & Manufacturer (Ma) & Firm that fabricates constructioncomponents and/or material: \\
\hline
\end{tabular}

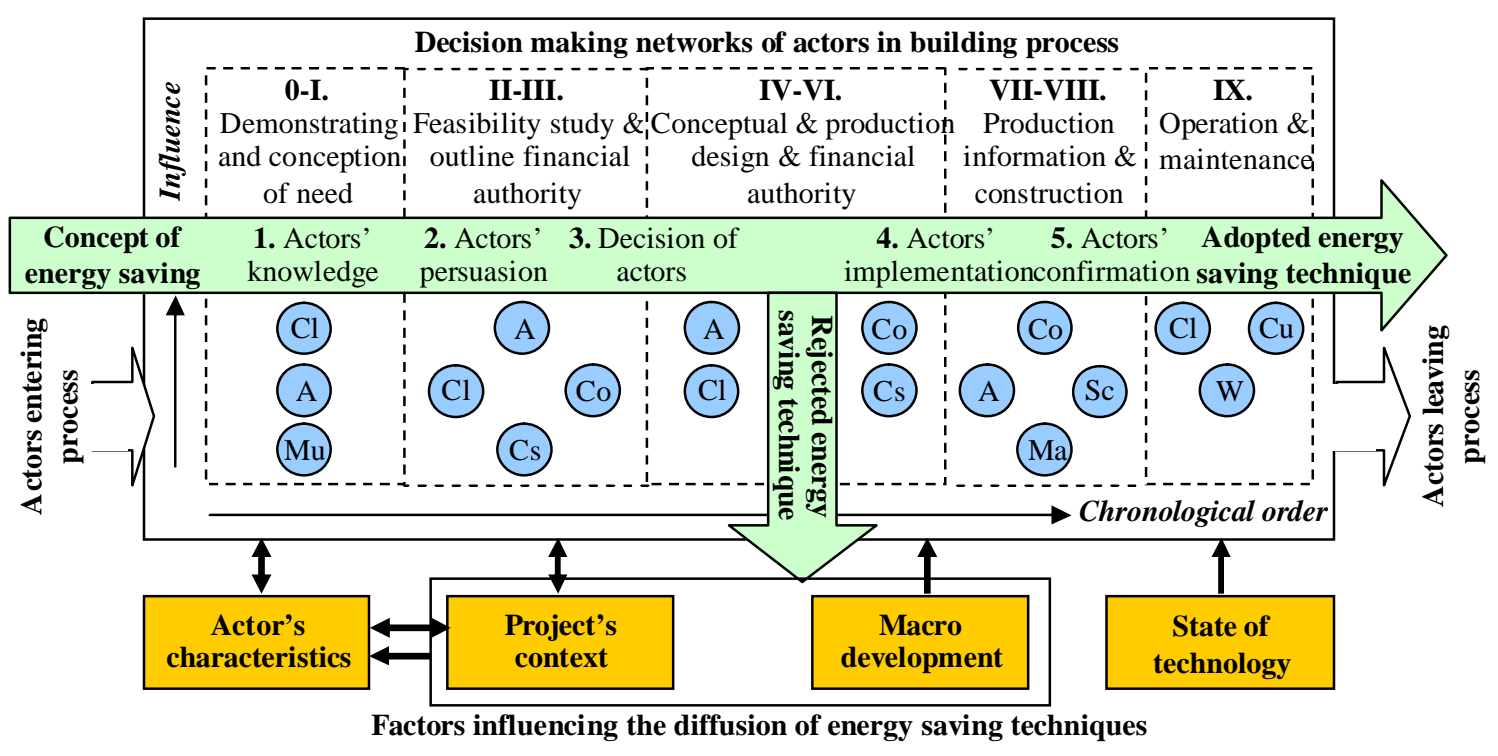

Fig. 1: Framework to analyse the adoption process in building processes. 


\section{Using the framework for social housing processes}

In this section we will operationalise the framework in order to analyse social housing projects by specifying the context in more detail. There are multiple reasons to study social housing projects. First, by the end of 2003 the total number of houses owned by social housing corporations was 2,420,500 being more than one third of the Dutch houses (Dekker, 2004). Secondly, the development of social housing seems to experience financial problems in achieving an improved energy performance. Thirdly, social housing corporations are considered to be highly experienced principals or property developers regarding real estate, but based on the investments costs less experience is expected to exist on the adoption of innovative techniques that go beyond the regulations in the Building Code. In this section we will further explain the context based on the four factors described in Figure 1.

\subsection{Macro development}

The context issue called "macro development" is mainly referring to the society at large (Dieperink et al, 2004). We clustered the developments in political, juridical and economic events within the construction industry in the Netherlands during the time-period 2003-2009.

Political developments: Starting from 2003 the government tried to encourage housing corporations to develop more houses to rent and to sell. Although, the number of houses developed by housing corporations increased, the government announced in 2006 that the corporations need to spend money on improving complete neighbourhoods. By 2010 the corporations will spend $€ 2.5$ billion per year for improving neighbourhoods. At this moment it is estimated that housing corporations own houses with a value of $€ 380$ billion (by means of the Valuation of Immovable Property Act), according to CBS the total VIPA-value of houses was approximately $€ 1,633$ billion in 2008 .

Legal developments: In the time period 2003-2009 the national Building Code of 2003 applied for new buildings. Regarding the energy use of buildings, a minimum insulation value of $2.5\left(\mathrm{~m}^{2} \cdot \mathrm{K}\right) / \mathrm{W}$, a minimum value for ventilation of $0.7 \mathrm{dm} /\left(\mathrm{s} \cdot \mathrm{m}^{2}\right)$, a maximum value for air infiltration of $0.2 \mathrm{dm} / \mathrm{s}$ per dwelling and an Energy Performance Coefficient (EPC) for dwellings of 1.0. The minimum floor height of $2.6 \mathrm{~m}$ and the height and width of door openings $(2.3 \mathrm{~m} \mathrm{x} 0.9 \mathrm{~m})$, also incorporated in the Building Code, influence the energy use indirectly. The EPC is based on an equation that relates forecasted and permissible energy use, incorporating the installed systems for heat production, heat resistance of the building shell and the size of the house, etc. By the beginning of 2006 the EPC was reduced to 0.8 .

Economic developments: Regarding the economic developments in this time period, it is important to address that in 2002 and 2003 there were small increases in the Gross Domestic Product (GDP) of only $0.1 \%$ and $0.3 \%$. After 2003 the GDP increased every year from $2.2 \%$ to $3.6 \%$, until the crisis started in the second half of 2008. On average the house prices increased from January 2003 to January 2009 by $23.8 \%$. The price to construct a new house for a housing corporation rose from $€ 90,000$.- in 2003 for $383 \mathrm{~m}^{3}$ to $€ 99,000$.- in 2008 for $385 \mathrm{~m}^{3}$. Prices of 
houses developed by private ownership or by project developers rose from $€$ 126,000.- for $542 \mathrm{~m}^{3}$ to $€ 147.000$,- for $563 \mathrm{~m}^{3}$.

\subsection{State of technology}

One can argue if the state of technology is a macro development. Nevertheless, technical developments are highly important in the field of energy saving techniques and the authors would like to address that for every building project the current state of available energy techniques should be regarded. However, stakeholders might attempt to rely on traditional techniques that are known to them by means of former projects. Last decade many new technologies were introduced in the housing market to save energy. At this moment the high efficiency natural gas boiler and insulation packages with a heat resistance of 3.0 $\mathrm{m}^{2} \cdot \mathrm{K} / \mathrm{W}$ are common in the Netherlands. The adoption rates of solar collectors, photovoltaic panels, and heat pumps are still rather low, although the techniques are already available for many years. The adoption rate of heat exchangers for waste water of showers is on the other hand relatively high. This technique has low investments costs, is easy to implement in new houses and has a high impact on the EPC. New techniques recently introduced in residential real estate are Phase Change Materials and LED-lighting for example. The availability of techniques will in the nearby future increase, because of growing environmental awareness and higher energy prices. Techniques that are already available will be improved and will probably become cheaper.

\subsection{Project's context}

Dutch social housing corporations have agreed to lower the energy consumption of their houses. Starting by October 2008, the natural gas consumption needs to be lowered by at least $20 \%$ within 10 years. Therefore, an energy performance certificate, which were introduced all around Europe in line with the Energy Performance Building Directive (EC, 2001), with classification B is desirable for existing houses or the performance should at least be improved by two steps in this A to $\mathrm{G}$ classification method. For new houses the energy consumption should be decreased by 25\%, starting from the first of January 2011. In 2015 the reduction should increase to $50 \%$.

Our main interest in this paper is the energy target. From the corporation's point of view the most important issue and "raison d'être" is to offer housing to all persons in society that are not able to obtain housing by themselves. These persons are most often restrained by financial means, but it is also possible that tenants have a physical or mental handicap.

\subsection{Actor's characteristics}

The objective of social housing corporations is to provide affordable housing of a proper quality for households with a minimum income. It is hard to achieve this objective in a market with relatively high land prices of $€ 341 .-1 \mathrm{~m}^{2}$ on average. Besides, the average building costs of a rented house are $€$ 86,000.- (excluding VAT) (Bouwend Nederland, 2007) and the adoption of energy saving techniques makes even higher investments necessary.

A subsidy on the rent is provided for the tenants of this type of residential real estate, when their income -minus the costs of renting- are below certain thresholds. These thresholds are solely based on the basic costs of hiring without service costs or energy costs. On average the basic costs are $€$ 402.- per month (Bouwend 
Nederland, 2007). This means that extra energy investments (that go beyond the basic regulations of the Building Code) can not be earned back by raising the monthly rent, because an increase will result in a subsidy stop for the tenant. However, the tenant does receive a lower energy bill and therefore will benefit from the investment done by the housing corporation.

\section{Results of the case study research}

After describing the context, this section presents four cases to gain insights in the influence of stakeholders in adopting energy saving techniques. These cases are provided by one social housing corporation in the Dutch municipality of Almelo. We analysed internal documents (like investment reports, specifications and drawings) and held interviews to specify the role of different actors and to fill in our framework. The corporation owns approximately 6,700 houses. Within the corporation different departments can be distinguished. One department has the obligation to initiate projects (client), another department manages the project (project manager), and a third department maintains and rents houses (customer). In some housing corporations these departments even form stand-alone firms, which only share one corporate identity for outsiders. By interviewing stakeholders and by studying written documents we were able to study the role and influence of every actor with the use of our framework.

\subsection{Case 1: The design and construction process of new social houses}

The first case (see Figure 2) studied is a project in which 73 new social houses were developed, of which 35 houses were commissioned by the client $(\mathrm{Cl} 1)$ described in the previous section. The other 38 houses were commissioned by another social housing corporation in the same municipality $(\mathrm{Cl} 2)$. In January 2005 a first proposal to develop the 35 houses shows that the houses are expected to be built with a standard EPC of 1.0 or less. Although the municipality requested to develop houses with a $10 \%$ lower EPC from the very first beginning, it took the social housing corporation more than eight months for incorporating this policy into their design process.

In November 2005, under pressure of the municipality $(\mathrm{Mu})$, the social housing corporations improved in het investment proposal the EPC ambition to 0.9. This mainly meant that the architect improved the heat resistance of floors, walls and roofs in the designs of the houses, resulting in EPC's with values of 0.81 to 0.95 with an average of 0.90 . In this case the municipality was the most important stakeholder in coming to a better energy performance than obliged by the National Building Code. This improved energy performance was commissioned by the client to the architect.

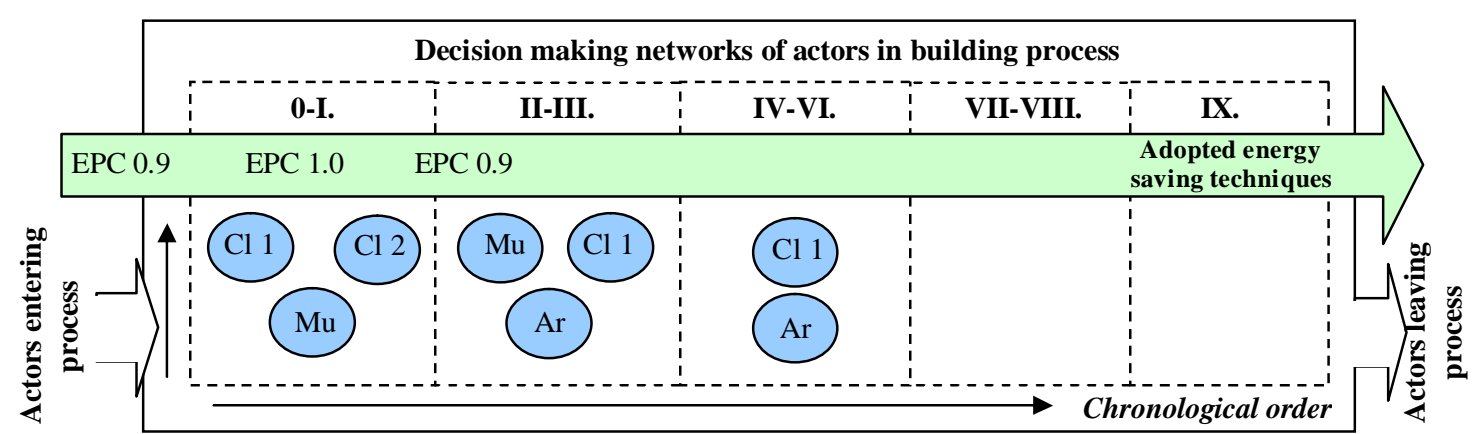

Fig. 2: Stakeholders in achieving an improved energy performance in case 1 


\subsection{Case 2: The design and construction process of new condos for seniors}

The second project is a housing project for elderly. In this project the social housing corporation $(\mathrm{Cl} \mathrm{1})$ collaborated with a local living and healthcare centre (Cl 2), as shown in Figure 3. The social housing corporation developed a high-rise apartment building containing 41 apartments and three penthouses. The initiation took place in December 2002 and the construction was completed in June 2009. In September 2003 the ambition was expressed to come to an improvement EPC of 0.9. Nevertheless, in 2005 an EPC of 0.98 was mentioned in the request for the building permit. The property developer, an internal department of the social housing corporation, used his influence to come to an improved EPC within the designs of the building. Although the client (Cl1), property developer (PD) and project manager (PM) belong to the same organisation, the project manager did not share the ambition in contrast with the property developer. In the next phase the EPC was therefore adjusted to 0.98 .

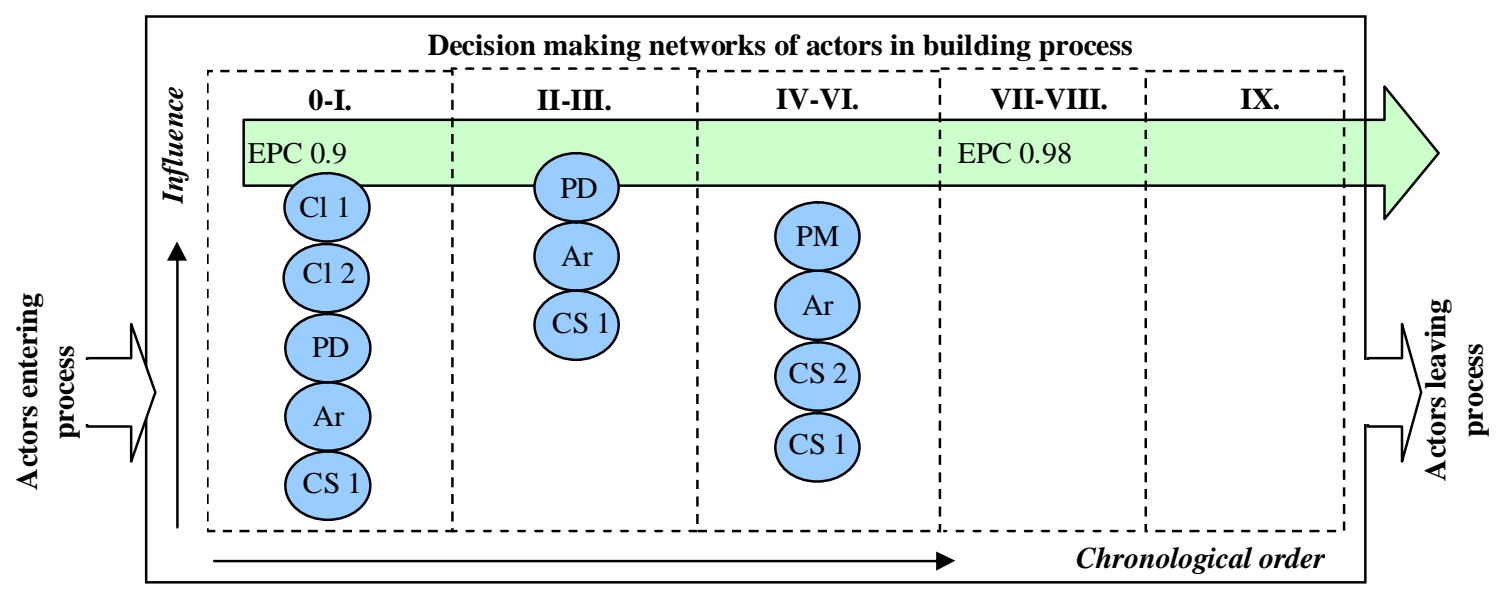

Fig. 3: Stakeholders influence in achieving an energy performance in case 2

\subsection{Case 3: The design and refurbishment of duplex houses}

The third case, that started in 2003, is a refurbishment process of 81 duplex houses, which were transformed to 54 dwellings. In this process e no explicit energy saving ambitions were specified in the project or investment proposal (see Figure 4). Nevertheless, the project manager introduced some measures to improve the energy performance because of the growing awareness that energy performance certification would be introduced for buildings in the whole European Union. Consequently the heat resistance of the roof, windows, walls and floors was improved.

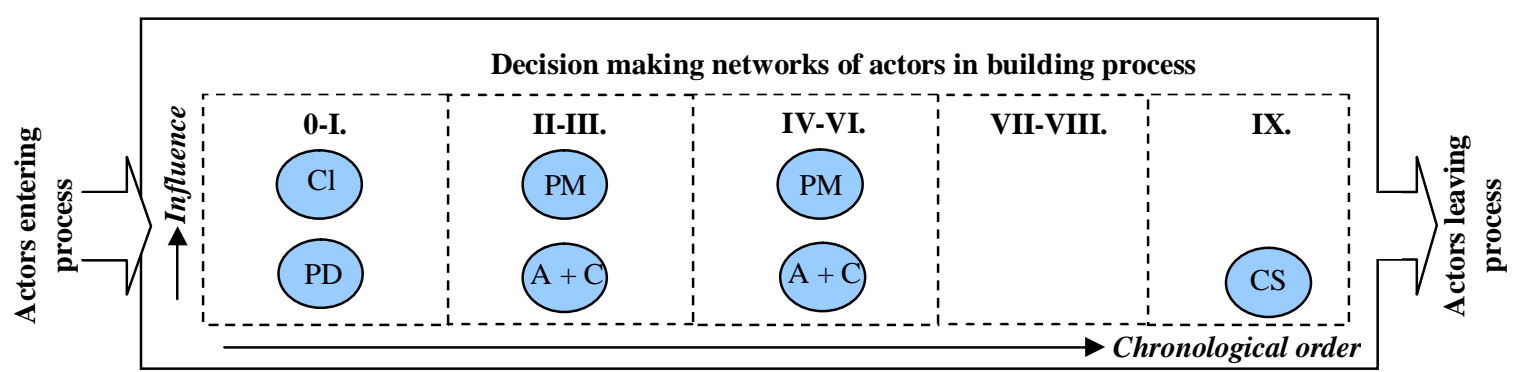

Fig. 4: Stakeholders in coming to an improved energy performance in case 3 
Afterwards, on request of the social housing corporation energy performance certificates were obtained for the 54 dwellings, showing so called Energy Indices of 1.13 to 1.21 or in other terms a label B. The energy label was given by an external organisation (CS), when the houses were already constructed and in use.

\subsection{Case 4: The design process for refurbishment of condos}

In 2004 a process was initiated on how to refurbish 102 condos, which were constructed in 1958 and renovated in 1988. After 45 months in which the plans were initiated, developed and a price was set by a contractor, the plans were not approved by the director, because the project was to expensive (see Figure 5). In 2009 the six buildings encompassing the 102 condos were demolished. The need for refurbishment was given by the fact that in 2008 the buildings would end their second life cycle; twenty years after the renovation of 1988. The plans were based on stripping the complete building to its carcass and adding extra condos with an EPC of 0.8 on top. At first an EPC of 0.95 was set as a target, but the possibility to receive subsidy triggered the project manager to ask for an improved energy performance. A new building shell would provide a better heat resistance for the existing condos.

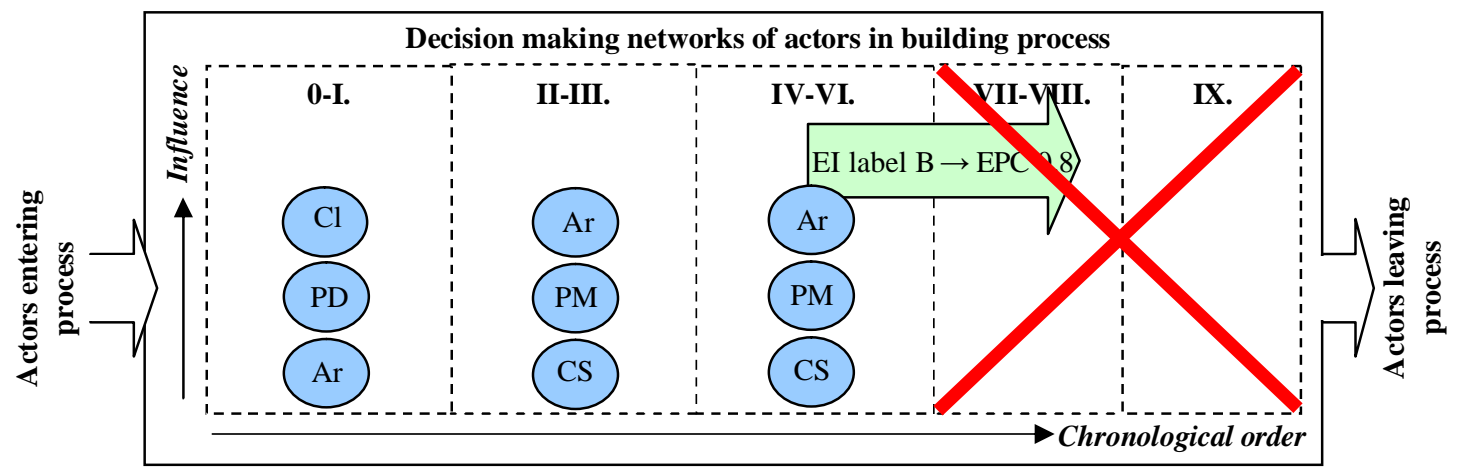

Fig. 5: Stakeholders in coming to an improved energy performance in case 4

\section{Discussion and conclusions}

Our research aims at improving the understanding of the role and influence of actors in the process of adopting energy techniques. A framework was developed based on the adoption process of innovations. The design processes in our cases show, however, that by using rather traditional technologies the social housing corporation was already able to comply with the compulsory EPC of the Building Code or the $10 \%$ lower EPC demanded by the municipality. Individual techniques seem not to dominate the discussions between stakeholders, but the EPC as an indicator is a major discussion topic. Rogers' aspect of relative advantage addresses the impact of separate techniques on the EPC and not the possible advantage of energy reduction for the user. On the other hand, the fact that traditional measures are being used in the studied cases shows the great relevance of Rogers' attribute of compatibility.

The influence of stakeholders differs strongly per project. Although the client, project manager, and project developer belong to the same organisation, they seem not to share one common vision regarding the energy performance. The municipality was able to force an improved EPC for the new buildings and ambitious project managers played an important role in the renovation projects. 
The impact of the architect may certainly not be neglected but his influence was only prevalent in the last case.

We can conclude that our framework helps to depict the transformations in relations between stakeholders during the design process. A clear analysis of the specific interests of stakeholders is needed to develop and implement successful energy savings measures. The paper further revealed the importance of studying adoption in its specific context, in this case the social housing setting.

Further research should take place on the roles of energy saving techniques and stakeholders in the building processes of offices.

\section{Acknowledgements}

The authors like to express their gratitude to Marieke Plegt for her research activities and SenterNovem for providing financial support for the present research "Exergy in the Built Environment" (LT02003).

\section{References}

Bouwend Nederland (2007). "De bouw in cijfers 2002-2006." (Dutch), Zoetermeer.

Cooke, R., Cripps, A., Irwin, A., Kolokotroni, M., "Alternative energy technologies in buildings: Stakeholder perceptions" Renewable Energy, 32, 2320-2333.

Dekker, S.M. (2004). "Prestaties van woningcorporaties in 2003, prestatieafspraken en toezicht in 2004." (Dutch), DGW/SR2004130681, Ministerie van VROM, 's-Gravenhage.

Dieperink, C., Brand, I., and Vermeulen, W. (2004). "Diffusion of energy-saving innovations in industry and the built environment: Dutch studies as inputs for a more integrated analytical framework." Energy Policy, 32(6), 773-784.

Entrop, A.G., Brouwers, H.J.H., Dewulf, G.P.M.R., and Halman, J.I.M. (2008). "Decision making processes and the adoption of energy saving techniques in residential and commercial real estate." Proceedings SB08, G. Foliente, T. Luetzkendorf, P. Newton and P. Paevere, eds., Melbourne, Australia

European Council (2002). "Energy Performance Building Directive (EPBD)" Directive 2002/91/EC of the European Parliament and Council.

Hartmann, A., Reymen, I.M.M.J., and Oosterom, G. van (2008) "Factors constituting the innovation adoption environment of professional public clients." Building, Research \& Information, 36(5), 436-449.

Kagioglou, M., Cooper, R., Aouad, G., Hinks, J., Sexton, M., and Sheath, D. (1998). "Process protocol" ISBN 090-289-619-9, University of Salford, Salford.

Raven, R.P.J.M. Mourik, R.M., Feenstra, C.F.J., Heiskanen, E. (2009) "Modulating societal acceptance in new energy projects: Towards a toolkit methodology for project managers." Energy, 34, 564-574.

Rogers, E.M. (2003). "Diffusion of innovations." $5^{\text {th }}$ edition, ISBN 0743222091 , Free Press, New York.

Vermeulen, W.J.V., and Hovens, J. (2006) "Competing explanations for adopting energy innovations for new office buildings." Energy Policy, 34 (17), 27192735. 